\title{
Ecological Correlates of Preschooler Obesity: A Multilevel Study
}

\author{
Yunhee Park ${ }^{1}$ \\ ${ }^{1}$ Department of Nursing, College of Medicine, Wonkwang University, South Korea \\ Correspondence: Yunhee Park, Department of Nursing, College of Medicine, Wonkwang University, 460, \\ Iksandae-ro, Iksan, Jeonbuk 54538, South Korea. Tel: 82-63-850-6028. E-mail: yhpark118@wku.ac.kr; \\ yhpark118@gmail.com
}

Received: September 22, 2019 Accepted: October 17, 2019 Online Published: November 3, 2019

doi:10.5539/gjhs.v11n13p50

URL: https://doi.org/10.5539/gjhs.v11n13p50

\begin{abstract}
Background: The risk factors for preschooler obesity at various levels have been identified, but little is known about the organizational-level factors of environments in which preschoolers spend long periods of time.

Methods: This study focused on factors at the organizational level and attempted multilevel modeling to appropriately estimate the effects with individual-level factors controlled. In 2013 and 2019, data from 295 and 112 preschoolers aged 2-5 years were collected, combined, and analyzed.

Results: At the individual level, mother's sedentary behavior was a significant factor, while at the organizational level, teacher's sedentary behavior was a significant factor.

Conclusion: Focus should be placed on developing obesity risk reduction intervention for this population group. Although there no statistical significance was observed, there is a need to improve the organizational environment such as reducing screen time and shortening the duration of study-focused programs. Moreover, further investigation in a prospective study is required to determine the evidence of these proposed interventions.
\end{abstract}

Keywords: obesity, preschooler, organization, multilevel modeling

\section{Introduction}

Childhood obesity has been an important public health issue for several years as it leads to physical illnesses and psychosocial problems (Ra, Yun, \& Cho, 2016), thereby having a negative effect on a child's growth and development. Moreover, childhood obesity often leads to obesity in adolescent and adult years (Kim, Lee, \& Lim, 2017) wherein the longer the period of time that a child is exposed to obesity, the longer the period of time he or she is exposed to the risk of developing chronic diseases (Reilly \& Kelly, 2011). Thus, nowadays, preschoolers are the major target for obesity prevention and health improvement programs where the age of target subjects is gradually decreasing.

Effective obesity prevention intervention for children needs a systematic investigation of various factors of obesity among preschoolers, for which we need to consider how the environment influences the childhood obesity. Children at this age have not yet formed a personal pattern of health-related habits or preferences, which means that they are most likely to be affected by a nurturing environment (Lee, Park, \& Lee, 2018). Particularly, the parenting or behavior of a mother who is a primary caregiver correlates significantly with childhood obesity; thus, a strategy where mothers are included in the intervention is relevant (Chen, Esquivel, Guo, Chesla, \& Tang, 2018).

Moreover, preschoolers spend most of their time at preschool institutions, such as nursery school or kindergarten; hence, factors related to these institutions must be closely examined as well (Lee et al., 2018). Specifically, almost all children aged 2-5 years in Korea attend kindergarten or nursery schools since the free childcare system was established by the Korean Government in 2012. As of the end of June 2018, 86.6\% of the total population of children aged 0-5 years attend preschool institutions (Korean Statistical Information Service [KOSIS], 2019). Preschoolers are exposed to healthy eating, physical activity (PA), and sedentary behavior (SB) and formation of health-related habits and acquisition of information from institution (H. K. Kim \& J. H. Kim, 2006); however, studies on the influence that institutions have on childhood obesity are rarely conducted despite its importance. Therefore, by highlighting the effects of preschool institutions on childhood obesity, it is expected that the results of this study will be used as basic data for developing effective interventions to reduce childhood obesity and to establish relevant policies. 
Ordinary least square (OLS) regression approach has been commonly used for estimating significant factors that contribute to childhood obesity. However, dependent variables at the individual level have independent variables at both individual and organizational levels. Taking the OLS regression approach seriously damages the study validity because it violates the independence assumption of the analysis unit when analyzing these hierarchical data (Raudenbush \& Bryk, 1986). Therefore, a multilevel modeling was used to estimate the effects of influential factors at the organizational level (Raudenbush \& Bryk, 1986).

This study established "What are the influential factors of preschooler obesity at individual and organizational levels?" as the research question and used multilevel modeling to investigate the significant effects of factors related to preschooler obesity. The research hypotheses in this study were: (1) Individual-level factors have a significant influence on childhood obesity, and (2) organizational-level factors have a significant influence on childhood obesity with the individual-level factors controlled.

\section{Methods}

\subsection{Study Design}

This study was a descriptive research that investigated the influential factors associated with preschooler obesity. The ecological model of McLeroy et al. (1988) was used to identify the significant factors of preschooler obesity and to reflect the multidimensional perspective of the environment, with human health being affected by the environment in many aspects. This study aimed to explore the influential factors at the organizational level using hierarchical data. The characteristics of institutions, which are the units of the group sharing the organizational environment, were defined as organizational-level factors, and the characteristics of the individuals were defined as individual-level factors. According to the ecological model, the attributes of mothers belong to the interpersonal-level factors, but since variation occurs across individual persons, it is included as an individual-level factor in this study (Figure 1).

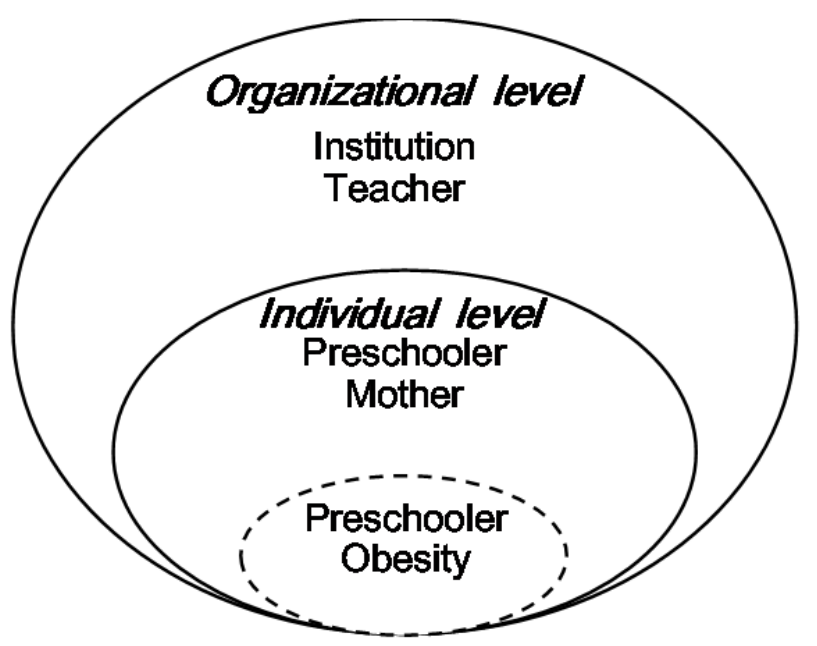

Figure 1. Conceptual framework of this study

PA: Physical activity, SB: Sedentary behavior

\subsection{Sample}

For primary data collection, we compared the number of children attending kindergarten or nursery of the KOSIS (2013) and selected five cities with the highest numbers. The convenience sampling method was used to select the institutions that agreed to participate in this study. The secondary data collection included four nursery institutions in Jeolla Provinces that were not selected in the primary data collection. The study subjects included children and teachers in 34 classes of 21 kindergarten or nurseries. A total of 417 out of 506 children completed the survey (response rate, $82.4 \%$ ), and 407 surveys ( 295 from the primary collection, 112 from the secondary collection) were used for the analysis after excluding incomplete responses. The teachers of all 34 classes were surveyed. We used the multilevel analysis method by Snijders and Bosker (1999) to take the number of groups, number of individuals in a group, and correlation coefficient within groups into consideration for calculating the appropriate number of samples. Based on this method, a total of 399 samples were needed, and the 407 samples of this study satisfied the 
sample size requirement for accuracy of parameter estimate and statistical power.

\subsection{Study Instruments}

\subsubsection{Anthropometric Measurements}

Anthropometric measurements obtained at the beginning of the semester in September were used for the primary data collection. For the four institutions that conducted the second data collection, height, and weight, measured by the teachers of each class using GL-300 model, were used (automatic height-weight meter, Saehan, Korea). Measurements were obtained with the shoes off and the clothes on and with a height of $0.1 \mathrm{~cm}$ and a weight of 0.1 $\mathrm{kg}$. To reduce discrepancies between teachers conducting measurements, the researcher trained the teachers about the measurement protocol before survey. Body mass index (BMI) was calculated and classified as normal, overweight, or obese groups using the BMI percentile for female and male based on the 2007 Korean National Growth Chart (Korea Center for Disease Control and Prevention \& Korean Pediatric Society [KCDC \& KPS], 2007). In this study, the overweight and obesity groups were classified into obesity category and used for analysis.

\subsubsection{Physical Activity Preference}

For estimating physical activity (PA) preference of children, we used the tool developed by Kim et al. (2014) consisting of 3 items. Cronbach's alpha was 0.71 in a previous study (Kim, Park, Park, \& Kim, 2014) and 0.78 in the present study.

\subsubsection{Physical Activity and Sedentary Behavior}

The short form of the International Physical Activity Questionnaire developed by the International Consensus Group for the Development of an International Physical Activity Questionnaire was used to measure physical activities of mothers and teachers (IPAQ, 2006), and metabolic equivalents (Mets) for a week were calculated. The SB level of mothers and teachers were measured by summing the hours spent on watching television (TV), playing video games, and using a computer for a week.

\subsubsection{Physical Activity Parenting and Barrier}

The mothers' PA parenting was measured using the Activity Support Scale for Multiple Groups developed by Davison et al. (2011), which was revised by Kim et al. to be applicable in the Korean population (Kim et al, 2014). Mother's barrier refers to the barrier a mother experiences when trying to prevent obesity in children, which consisted of nine items developed by Kim et al. (2014). Cronbach's alpha was 0.72 and 0.69 in a previous study (Kim et al, 2014) and 0.74 and 0.70 in the present study

\subsubsection{Obesity-Related Knowledge}

Obesity-related knowledge was measured using a tool developed by Lee and Yang (2011) that was applicable to daycare center workers. The tool consisted of 30 true or false questions, and a higher score indicated a higher level of knowledge of obesity.

\subsubsection{Organizational Environments}

Regarding the obesity-related environment at each institution, screen time, programs focusing on physical activities, whether obesity prevention education is conducted, and study-focused programs were surveyed. Screen time was measured by the teacher's observation from the moment that the child arrives at the preschool institution until leaving the institution. Whether PA-focused and study-focused programs were conducted for 30 minutes a day on average and whether obesity prevention education programs were conducted were also measured using binary response.

\subsection{Ethical Considerations and Data Collection}

The protocol of this study was conducted after obtaining the approval (IRB 2013-0028-1, \& WKIRB-201905-SB-045) from the institutional review board of the institution to which the researcher belongs. The purpose and method of this study were explained to the study subjects, whose mothers and teachers provided written informed consent for inclusion in the study. The study subjects were rewarded, and all the tools used in the study were only after permission was obtained from the original authors.

The primary survey was conducted for 2 months from October to November in 2013, and the secondary survey was conducted in June 2019. The mother, who is a caregiver, completed the survey questionnaire regarding the variables of her preschooler, while mothers and teachers completed the self-administered questionnaire. Teachers trained by the researchers about survey protocol distributed the informed consent document and survey questionnaire to class students. The teachers instructed the mother to check the consent document and questionnaire as the child returned home, and to fill out them if she was willing to participate in the study. If the 
mothers had any questions about the research, the teacher guided the mother by contacting the researcher and understanding research details.

\subsection{Analysis}

Stata software package version 13 (Stata, College Station, Texas) was used for analysis. To establish a multilevel regression model of preschooler obesity, univariate analysis was performed, and variables that were statistically significant with a significance level $\alpha<0.05$ were included in the model, and a random intercept model with no consideration of the variance of regression coefficients was chosen. First, whether the variation in the organizational (institutional) level was statistically significant using the null model was tested. The intra-class correlation coefficient (ICC) $(\rho)$ was 0.191 , indicating that $19.1 \%$ of the overall variance occurred due to the difference between institutions. Therefore, it was proven that conducting multilevel analysis was appropriate in this study.

The effects of individual-level variables on preschooler obesity were estimated through the individual model; subsequently, the effects of organizational-level variables estimated through the individual-organizational model with individual-level variables controlled. The maximum likelihood estimate method was used to estimate the multilevel model.

\section{Results}

\subsection{Individual-Level Characteristics and Difference in the Risk of Obesity}

The age of preschoolers in this study ranged evenly from 2 to 5 years, and the number of female preschoolers $(50.4 \%)$ was slightly higher than that of male preschoolers. The preschooler's average score of PA preference was $9.05( \pm 2.17)$ out of 15 . The mothers' PA index was $1763.04( \pm 1955.70)$ Mets/week, and their SB was $9.56( \pm 7.44)$ hours/week. PA parenting, PA barrier, and healthy eating (HE) barrier were $19.52( \pm 3.25), 8.78( \pm 3.05)$, and 8.88 $( \pm 2.66)$, respectively. The percentage of stay-at-home mothers was $59.2 \%$, which was higher than that of working mothers. The highest response for the monthly household income was 3-5 million Korean won (43.1\%). The SB of a mother was the only individual-level variable that had a significant difference for preschooler obesity $(\mathrm{p}<$ $0.001)$.

\subsection{Organizational-Level Characteristics and Difference in the Risk of Obesity}

A total of $66.8 \%$ of the preschoolers attended an institution that offers greater than 30 minutes of screen time to preschoolers per day, and $27.3 \%$ of the children attended an institution that operates a study-focused program greater than 30 minutes a day.

The variables among organizational-level factors that showed a significant difference are teacher's $\mathrm{SB}(\mathrm{p}<.001)$, teacher's educational level $(\mathrm{p}=.001)$, and screen time at the institution $(\mathrm{p}=.040)$ (Table 1$)$.

Table 1. Organizational level characteristics \& differences in the Risk of Obesity by Organizational factors

\begin{tabular}{|c|c|c|c|c|c|c|c|c|c|}
\hline & & \multicolumn{3}{|c|}{$\begin{array}{l}\text { Total } \\
(n=407)\end{array}$} & \multicolumn{2}{|c|}{$\begin{array}{l}\text { Normal } \\
(\mathrm{n}=323)\end{array}$} & \multicolumn{2}{|c|}{$\begin{array}{l}\text { Overweight \& Obesity } \\
(\mathrm{n}=84)\end{array}$} & \multirow[t]{2}{*}{$p$ Value } \\
\hline & & \multicolumn{2}{|l|}{$M$} & $S D$ & $M$ & $S D$ & $M$ & $S D$ & \\
\hline Teacher's knowledge & & \multicolumn{2}{|c|}{18.67} & 3.09 & 18.52 & 3.01 & 19.25 & 3.33 & .054 \\
\hline Teacher's PA (Mets/week) & & \multicolumn{2}{|c|}{976.62} & 1063.92 & 993.65 & 1126.92 & 911.11 & 777.59 & .527 \\
\hline \multirow[t]{2}{*}{ Teacher's SB (hours/week) } & \multicolumn{3}{|c|}{8.40} & 6.69 & 7.80 & 6.56 & 10.71 & 6.73 & $<.001$ \\
\hline & Category & & $n$ & $\%$ & $n$ & $\%$ & $n$ & $\%$ & \\
\hline \multirow[t]{2}{*}{ Teacher's Career (year) } & $\leq 1$ & & 209 & 51.4 & 159 & 76.1 & 50 & 23.9 & $.111^{\dagger}$ \\
\hline & $>1$ & & 198 & 48.6 & 164 & 82.8 & 34 & 17.2 & \\
\hline \multirow[t]{2}{*}{ Teacher's Education level } & \multicolumn{2}{|c|}{$\leq$ College } & 179 & 48.6 & 127 & 70.9 & 52 & 29.1 & $.001^{\dagger}$ \\
\hline & \multicolumn{2}{|c|}{$\geq$ University } & 189 & 51.4 & 161 & 85.2 & 28 & 14.8 & \\
\hline
\end{tabular}




\begin{tabular}{llllllllll}
\hline Institution type & Kindergarten & 175 & 43.0 & 142 & 81.1 & 33 & 18.9 & $.460^{\dagger}$ \\
& Nursery & 232 & 57.0 & 181 & 78.0 & 51 & 22.0 & $.363^{\dagger}$ \\
\hline PA-focused program & $\geq 30 \mathrm{mim} /$ day & 272 & 66.8 & 111 & 82.2 & 24 & 20.6 & 22.1 \\
& $<30 \mathrm{mim} /$ day & 135 & 33.2 & 212 & 77.9 & 60 & & \\
& $\geq 30 \mathrm{mim} /$ day & 143 & 35.1 & 105 & 73.4 & 38 & 26.6 & $.040^{\dagger}$ \\
\hline Screen time & $<30 \mathrm{mim} /$ day & 264 & 64.9 & 218 & 82.6 & 46 & 17.4 & \\
\hline Study focused program & $\geq 30 \mathrm{mim} /$ day & 111 & 27.3 & 81 & 73.0 & 30 & 27.0 & $.055^{\dagger}$ \\
& $<30 \mathrm{mim} /$ day & 296 & 72.7 & 242 & 81.8 & 54 & 18.2 & $.713^{\dagger}$ \\
\hline Obesity prevention education & Yes & 188 & 46.2 & 151 & 80.3 & 37 & 19.7 & 21.5 \\
\hline
\end{tabular}

PA: Physical Activity, SB: Sedentary Behavior, HE: Healthy Eating.

†Fisher's exact test.

\subsection{Factors Affecting Preschoolers' Obesity in Individual and Organizational Level}

The results of multilevel modeling are shown in Table 2. To test hypothesis 1, mother's SB was included in the regression model (Model 1). The mother's SB $(p<.001)$ showed a positive effect on preschooler obesity. The ICC ( $\rho$ ) was 0.238 , indicating that the variance that cannot be explained even after the mother's SB was considered remained $23.8 \%$. Hence, it is necessary to consider model 2 with additional explanatory variables at the organizational level. In model 2, teacher's SB $(\mathrm{p}<.001)$ had a positive effect, while teacher's educational level and screen time were not statistically significant.

In the null model, the variance component at organizational level was 0.78 ; however, it decreased to 0.58 when independent variables at the organization level were added to model 2 to explain preschooler obesity. Hence, the $\mathrm{R}^{2}$ of the organizational-level model was $25.6 \%$.

Table 2. Multilevel model analysis in obesity-related factors of preschoolers

\begin{tabular}{|c|c|c|c|c|c|c|c|c|c|}
\hline \multirow{3}{*}{$\begin{array}{l}\text { Model } \\
\text { Parameter } \\
\text { Fixed effect }\end{array}$} & & \multirow{2}{*}{\multicolumn{4}{|c|}{$\begin{array}{l}\text { Model } 1 \\
\text { Individual model }\end{array}$}} & \multirow{2}{*}{\multicolumn{4}{|c|}{$\begin{array}{l}\text { Model } 2 \\
\text { Individual-Organizational model }\end{array}$}} \\
\hline & & & & & & & & & \\
\hline & & $\beta$ & S.E. & OR & $p$ & $\beta$ & S.E. & OR & $p$ \\
\hline \multirow{2}{*}{ Level 1} & Intercept & -2.22 & 0.27 & 0.11 & $<.001$ & -2.77 & 1.42 & 0.06 & .070 \\
\hline & Mother's SB & 0.08 & 0.02 & 1.08 & $<.001$ & 008 & 0.02 & 1.08 & $<.001$ \\
\hline \multirow{3}{*}{ Level 2} & Teacher's Edu & & & & & 0.38 & 0.45 & 0.06 & .409 \\
\hline & Teacher's SB & & & & & 0.13 & 0.03 & 1.13 & $<.001$ \\
\hline & Screen time & & & & & 1.04 & 0.43 & 1.04 & .993 \\
\hline Random effect & & $\mathrm{SD}$ & $\tau$ & $\chi^{2}$ & $p$ & $\mathrm{SD}$ & $\tau$ & $\chi^{2}$ & $p$ \\
\hline level $2, u_{0}$ & & 1.01 & 1.03 & 65.762 & $<.001$ & 0.76 & 0.58 & 36.831 & .003 \\
\hline $\operatorname{ICC}(\rho)$ & & 0.238 & & & & 0.150 & & & \\
\hline
\end{tabular}

SB: Sedentary Behavior, Edu: Education level.

$\tau$ : variance of $u_{0}$. 


\section{Discussion}

This study aimed to determine how the factors related to preschool institution affect preschooler obesity. BMI of the preschoolers was calculated using the height and weight measured in the study, where the male and female children were separately classified into the normal, overweight, and obese groups according to the BMI percentile based on the Korean National Growth Chart (KCDC \& KPS, 2007). Both the overweight and obese groups were included in the obese category for the study. Out of the 407 preschoolers who participated in the study, 20.6\% belonged to the obese category, of which $9.6 \%$ were obese, and $11.0 \%$ were overweight. These figures were lower than $31 \%$ in the USA or $26 \%$ in the UK (World Health Organization, 2011), but it was an increase from $12.6 \%$ including both overweight and obesity as reported in the Korea National Health and Nutrition Examination Survey (Ministry of Health \& Welfare, Korea Centers for Disease Control \& Prevention, 2013). This study was conducted in 2013 and 2019; thus, there is a possibility of increased prevalence in preschooler obesity, signifying that active intervention is needed to reduce the risks of developing preschooler obesity.

Preschoolers in Korea spend most of their time at kindergarten or nursery. The preschool stage is when a child's attitude or pattern related to food preference, eating behavior, and PA starts to form (Duncan, Hansen, Wang, Wan, \& Zhang, 2015); thus, the environment at the kindergarten or nursery or the teachers' behavior at the kindergarten or nursery may have the greatest impact on preschoolers' health-related behavior. The study results showed that an increase in the teacher's SB led to an increase in the obesity rate among children. As a mother, who is a primary caregiver, shapes a child's attitude or behavior (Sonneville, Rifas-Shiman, Kleinman, Gortmaker, Gillman, \& Taveras, 2012), we can assume that the teacher, who also spends a long period of time with children, had the same degree of influence. The higher rate of SB from the mother led to the higher rate of SB from the child (Goncalves, Byrne, Viana, \& Trost, 2019), which was also exhibited in this study. When the mother has active lifestyle patterns, the child also stays active just by being with the mother, which reduces the risk of obesity. On the contrary, if the mother prefers sedentary behavior, the child also stays sedentary along with the mother, which increases the risk of obesity. However, the mechanism of how the teacher's SB affects the obesity in children has not been verified. Because similar kinds of programs are operated at institutions, it is not certain to what extent the teacher's individual behavior affects an individual child. We can assume that physical activities at home might have decreased due to the modeling of the teacher who exhibited the most sedentary behavior. As the SB of class teacher in this study had a significant effect on childhood obesity, even with individual-level factors controlled, and the behavior of a teacher has a great impact on children in Korean society where teachers are typically respected as role models (Ra, Yun, \& Cho, 2016), a strategy for reducing the SB of the teacher must be included to prevent childhood obesity. Moreover, repeated studies need to be conducted to clearly identify how teacher's behaviors affect the occurrence of obesity among children.

Greater than $90 \%$ of kindergarten and nursery in Korea are operating various kinds of cognitive development programs because the importance of learning letters, numbers, or foreign language is becoming more prevalent. Greater than $70 \%$ of these institutions currently incorporate those programs in their daily curriculum, concentrating more on study-focused programs (Woo, Y. S. Kim, Lee, \& H.S.Kim, 2009). Participating in a study-focused program can be considered as SB in which the longer they spend on study-focused programs, the higher the chance of developing childhood obesity (Jouret et al., 2007). Both screen time and the duration of study-focused programs at the institution were inspected in this study; however, they were not included in the regression analysis model because the univariate analysis results were insignificant. SB causes not only imbalanced energy consumption, which directly leads to the risk of developing obesity, but also inactivity in adult years by forming habits of avoiding physical activities. In recent years, as children's exposure to smartphones has increased, the portion of child screen time has surpassed that of watching TV or playing computers (Ra \& Chae, 2014). Using smartphones can create an environment where preschoolers' screen time increases, hence leading to a high risk of addiction (Park, 2019). Thus, a strategy is required to ensure that teachers and parents recognize the risks and reduce the screen time by thoroughly monitoring the screen time of preschoolers in the institution or at home.

In this study, whether the institution is offering obesity prevention education had no significance in preschooler obesity. However, the mothers of preschoolers agree that childhood obesity prevention programs must be provided from institutions, and teachers also thought that nutrition education is important for preventing obesity among preschoolers (Pyo \& Kang, 2014). In this study, teachers were asked only if obesity prevention education is offered at their kindergarten or nursery, but detailed curriculum content or the time spent on education was not evaluated; thus, there is a limitation in estimating the effects of obesity prevention teaching variable. The teachers have a low level of knowledge regarding nutrition (Park \& Lee, 2001), academic curriculums do not incorporate enough physical activities and information on nutrition, and a supportive system does not exist for better education, all of 
which prevent the teachers from giving proper education on obesity prevention (Pyo \& Kang, 2014). There may be a variation in contents and quality of education provided by institutions without relevant policies established. According to the previous studies, the discrepancies in kindergarten teachers' ability to conduct nutrition education and their level of knowledge between urban and rural areas are very significant (Kim, C. Y. Lee, T. W. Lee, \& Ham, 2006). This is due to the lack of policy to ensure the quality of teachers and the essential curriculum. Moreover, preschool teachers are human resource of the community who can provide education on obesity for children and education on general health for parents. Therefore, a policy should be established to expand the opportunities for supplementary education that allows teachers to acquire knowledge on obesity and general health.

Obesity-related parenting variables at the individual level did not have a statistically significant difference on the univariate analysis, which differs from the findings in prior studies stating that appropriate parenting for PA, SB, and $\mathrm{HE}$ can reduce the risks of obesity by controlling and restricting food (Kremers et al, 2013). Children with high parenting scores may have lower risk of developing obesity as they have HE habit and PA levels; however, this may be due to the fact that the parents of children who are already obese are encouraging their children to be more active and adapt healthy eating habits to help them lose weight and become healthier. Because of the limitation of this cross-sectional study, it is difficult to explain the causal association between these factors that must be examined in a prospective study.

\section{Conclusions}

In order to effectively reduce the risk of obesity in preschooler, it is important to find practical factors that can be changed first, and that the changes can effectively reduce the risk of obesity. This study focused on identifying factors at the organizational level as well as individual-level factors with using a multilevel modeling to reasonably estimate the effects of variables. Mother's sedentary behavior at the individual level, and teacher's sedentary behavior at organizational level have found to be significant factors, therefore they should be included in the intervention for reducing obesity risk for preschoolers. In addition, the institutional environment such as screen time and study-focused program is necessary to be improved although they were not statistically significant, and further prospective studies are needed to establish the evidence to support this.

\section{Acknowledgements}

This study was supported by the research foundation of Wonkwang University, 2019.

\section{Competing Interests Statement}

The author declares that there are no competing or potential conflicts of interest.

\section{References}

Korean Statistical Information Service. (2019). Statistics on childcare facilities and user. Retrieved September 1, 2019, from http://kosis.kr/search/search.do

Korean Statistical Information Service. (2013). Statistics on childcare facilities and user. Retrieved September 1, 2019, from http://kosis.kr/search/search.do

Benjamin, S. E., Rifas-Shiman, S. L., Taveras, E. M., Haines, J., Finkelstein, J., Kleinman, K., \& Gillman, M. W. (2009). Early child care and adiposity at ages 1 and 3 years. Pediatrics, 124(2), 555-562. https://doi.org/10.1542/peds.2008-2857

Chen, J. L., Esquivel, J. H., Guo, J., Chesla, C. A., \& Tang, S. (2018). Risk factors for obesity in preschool-aged children in China. International Nursing Review, 65(2), 217-224. https://doi.org/10.1111/inr.12371

Davison, K. K., Li, K., Baskin, M. L., Cox, T., \& Affuso, O. (2011). Measuring parental support for children's physical activity in white and African American parents: the Activity Support Scale for Multiple Groups (ACTS-MG). Preventive Medicine, 52(1), 39e43. https://doi.org/10.1016/j.ypmed.2010.11.008

Duncan, D. T., Hansen, A. R., Wang, W., Yan, F., \& Zhang, J. (2015). Change in misperception of child's body weight among parents of American preschool children. Childhood Obesity, 11(4), 384-393. https://doi.org/10.1089/chi.2014.0104

Goncalves, W. S. F., Byrne, R., Viana, M. T., \& Trost, S. G. (2019). Parental influences on screen time and weight status among preschool children from Brazil: a cross-sectional study. International Journal of Behavioral Nutrition and Physical Activity, 16(1), 27. https://doi.org/10.1186/s12966-0190788-3

International Physical Activity Questionnaire. International Physical Activity Questionnaire (IPAQ) short form: Korean version. Retrieved September 1, 2019, from: https://docs.google.com/viewer?a=v\&pid=sites\&srcid=ZGVmYXVsdGRvbWFpbnx0aGVpcGFxfGd4OjVi 


\section{MGM2OWI3Mj c5NjBjMTE.}

Jouret, B., Ahluwalia, N., Cristini, C., Dupuy, M., Nègre-Pages, L., Grandjean, H., \& Tauber, M. (2007). Factors associated with overweight in preschool-age children in southwestern France. The American Journal of Clinical Nutrition, 85(6), 1643-1649. https://doi.org/10.1093/ajen /85.61643

Kim, H. K., \& Kim, J. H. (2006). A preliminary study on nutrition education for preschool children in day-care center-dietary habit and nutrition knowledge. Journal of the Korean Society of Food Science and Nutrition, 35(7), 866-873. https://doi.org/10.3746/jkfn.2006.35.7.866

Kim, J., Lee, I., \& Lim, S. (2017). Overweight or obesity in children aged 0 to 6 and the risk of adult metabolic syndrome: a systematic review and meta-analysis. Journal of Clinical Nursing, 26, 3869-3880. https://doi.org/10.1111/jocn.13802

Kim, H. S., Lee, C. Y., Lee, T. W., \& Ham, O. K. (2006). Health education and health care in daycare centers for preschoolers. Journal of Korean Society for Health Education and Promotion, 23(1), 109-123.

Kim, H. S., Park, Y. H., Park, H. B., \& Kim, S. H. (2014). Estimation of effects of factors related to preschooler body mass index using quantile regression model. Asian Nursing Research, 8(4), 293-299. https://doi.org/10.1016/j.anr.2014.07.005

Korea Center for Disease Control and Prevention \& The Korean Pediatric Society. (2007). 2007 Korean National Growth Charts. Retrieved September 1, 2019, from www.cdc.go.kr

Kremers, S., Sleddens, E., Gerards, S., Gubbels, J., Rodenburg, G., Gevers, D., \& van Assema, P. (2013). General and food-specific parenting: measures and interplay. Childhood Obesity, 9(s1), S-22. https://doi.org/10.1089/chi.2013.0026

Lee, Y. R., Park, S. N., \& Lee, M. R. (2018). Needs for children's health promotion education as perceived by child care center teachers and mothers. Child Health Nursing Research, 24(2), 186-198. https://doi.org/10.4094/chnr.2018.24.2.186

Lee, D. J., \& Yang, Y. O. (2011). Knowledge related to child obesity of child daycare center worker. Journal of Korean Academy of Child Health Nursing, 17(4), 247-255. https://doi.org/10.4094/jkachn.2011.17.4.247

McLeroy, K.R., Bibeau, D., Steckler, A., \& Glanz, K. (1988). An ecological perspective on health promotion programs. Health Education Quarterly, 15, 351-371. https://doi.org/10.1177/109019818801500401

Ministry of Health \& Welfare, Korea Centers for Disease Control \& Prevention (2013). Korea Health Statistics 2012: Korea National Health and Nutrition Examination Survey

Park, Y. (2019). Factors affecting smartphone exposure time of preschoolers. Journal of Learner-Centered Curriculum and Instruction, 19(1), 159-174. https://doi.org/10.22251/jlcci.2019.19.1.159

Park, G. A., \& Lee, J. H. (2001). Child care teachers' knowledge regarding nutrition for infants, toddlers and young children. Journal of Korea Open Association for Early Childhood Education, 5, 51-65.

Pyo, S. H., \& Kang, H. J. (2014). A study on the actual state of nutrition knowledge, dietary attitude, eating behavior, physical ability and locomotion of children aged 5 years in Siheung-city. The Korean Journal of Food and Nutrition, 27(5), 760-770. https://doi.org/10.9799/ksfan.2014.27.5.760

Ra, J. S., \& Chae, S. M. (2014). Factors influencing maternal support for physical activity of preschool children. Child Health Nursing Research, 20(1), 30-38. https://doi.org/10.4094/chnr.2014.20.1.30

Ra, J. S., Yun, H. J., \& Cho, Y. H. (2016). Teachers' influence on weight perceptions in preschool children. Applied Nursing Research, 31, 111-116. https://doi.org/10.1016/j.apnr.2016.01.005

Raudenbush, S. W., \& Bryk, A. S. (1986). A hierarchical model for studying school effects. Sociology of Education, 59(1), 1-17. https://doi.org/10.2307/2112482

Reilly, J. J., \& Kelly, J. (2011). Long-term impact of overweight and obesity in childhood and adolescence on morbidity and premature mortality in adulthood: systematic review. International Journal of Obesity (London), 35(7), 891-898. https://doi.org/10.1038/ijo.2010.222

Tom Snijders, T., \& Bosker, R. (2012). Multilevel Analysis: An Introduction to Basic and Applied Multilevel Analysis. London: Sage.

Sonneville, K. R., Rifas-Shiman, S. L., Kleinman, K. P., Gortmaker, S. L., Gillman, M. W., \& Taveras, E. M. (2012). Associations of obesogenic behaviors in mothers and obese children participating in a randomized 
trial. Obesity, 20(7), 1449-1454. https://doi.org/10.1038/oby.2012.43

Woo, N. H., Kim, Y. S., Lee, E. J., \& Kim, H. S. (2009). Examining mothers' perception and current status concerning their children's education and nurturing in the low birthrate era. Journal of Future Early Childhood Education, 16(3), 297-325.

World Health Organization. (2011). Global Status report on noncommunicable diseases 2010.

\section{Copyrights}

Copyright for this article is retained by the author(s), with first publication rights granted to the journal.

This is an open-access article distributed under the terms and conditions of the Creative Commons Attribution license (http://creativecommons.org/licenses/by/4.0/). 